\title{
Living-Learning Community for Women in Computer Science at Rutgers
}

\author{
Rebecca N. Wright \\ Rutgers University \\ rebecca.wright@rutgers.edu
}

\author{
Sally J. Nadler \\ Rutgers University \\ sjn6@echo.rutgers.edu
}

\author{
Thu D. Nguyen \\ Rutgers University \\ tdnguyen@cs.rutgers.edu
}

\author{
Cynthia N. Sanchez Gomez \\ Rutgers University \\ cysanche@echo.rutgers.edu
}

\author{
Heather M. Wright \\ Computing Research Association \\ heather@cra.org
}

\begin{abstract}
We describe our experience developing and running a Computer Science Living-Learning Community (LLC) for first-year women at Rutgers University, now in its third year. Each year, around 20 first-year undergraduate women who intend to major in computer science (CS) apply and are selected to participate. LLC participants live in a common residence hall and are provided with an educational, mentoring, and community-building program that supports their progress as students and CS majors. Participants take a "house course," Great Ideas and Insights in Computer Science, as a group, and also take a course on Knowledge and Power: Issues in Women's Leadership. Program activities include study sessions and industry interactions, as well as opportunities to participate in K-12 outreach programs, hackathons, and computing research. To evaluate the program, participants and a similar comparison group are surveyed at the beginning and end of the academic year and a focus group is conducted with program participants. Program participants find the program valuable and would recommend it to others, but both program participants and the comparison group report some lack of confidence in their potential success as computer scientists.
\end{abstract}

\section{CCS CONCEPTS}

- Social and professional topics $\rightarrow$ Computer science education; Women;

\section{KEYWORDS}

living-learning communities; undergraduate education; gender and diversity

\section{ACM Reference Format:}

Rebecca N. Wright, Sally J. Nadler, Thu D. Nguyen, Cynthia N. Sanchez Gomez, and Heather M. Wright. 2019. Living-Learning Community for Women in Computer Science at Rutgers. In Proceedings of the 50th ACM Technical Symposium on Computer Science Education (SIGCSE '19), February 27-March 2, 2019, Minneapolis, MN, USA. ACM, New York, NY, USA, 7 pages. https://doi.org/10.1145/3287324.3287449

Permission to make digital or hard copies of all or part of this work for personal or classroom use is granted without fee provided that copies are not made or distributed for profit or commercial advantage and that copies bear this notice and the full citation on the first page. Copyrights for components of this work owned by others than the author(s) must be honored. Abstracting with credit is permitted. To copy otherwise, or republish, to post on servers or to redistribute to lists, requires prior specific permission and/or a fee. Request permissions from permissions@acm.org.

SIGCSE'19, February 27-March 2, 2019, Minneapolis, MN, USA

(C) 2019 Copyright held by the owner/author(s). Publication rights licensed to ACM ACM ISBN 978-1-4503-5890-3/19/02.

https://doi.org/10.1145/3287324.3287449

\section{INTRODUCTION}

Undergraduate computer science enrollments have risen substantially in the last decade nationally, most years with double-digit percentage increases $[2,30]$. But the percentage of women remains stubbornly low, at $19 \%$ of undergraduate computer science graduates in the United States and Canada in 2017, according to the Computing Research Association's Taulbee Survey [30]. In addition to the social justice issues associated with this disparity, the low participation of women in computer science (CS) negatively impacts the robustness of the computing workforce and the level of technical innovation possible in CS-based organizations. Increasing the participation of women in CS has been challenging because of a number of factors. For example, women feel out-of-place and unsupported in the current male-dominated environment $[6,17]$ and women report that they do not feel CS is connected to addressing real-world problems and helping people [18].

In order to help support undergraduate women to succeed as CS majors, Rutgers University, a large public R1 institution, has developed a living-learning community (LLC) for first-year undergraduate women in CS. Through an immersive educational and community-building experience, the program is designed to promote student engagement and success in CS. Specifically, the LLC incorporates mentoring, academic and professional development activities, a community of peers for friendship and academic support, and exposure to the issues and applications of CS. Our hope is that for first-year undergraduate women who are interested in majoring in CS, participation in the LLC will lead to participants declaring a CS major and persisting in the major.

Living-learning communities are programs based in college residence halls that link students' living environments with a particular academic theme or topic, supported by access to additional academic resources and support. LLCs have been shown to have a positive impact on undergraduate students in their first year and to provide students with a deeper and more integrated learning experience $[9,22,24]$. Living-learning communities for women in STEM have been shown to have positive impacts [14] and are considered a best practice by the Association of American Colleges and Universities, the National Science Foundation, the National Academies, and the American Association for University Women [1, 5, 8, 10]. Participation in living-learning programs has been shown to benefit undergraduates in both academic and social contexts including the transition to college, first-year retention, grade point average, civic engagement, critical thinking, and engaging in deep intellectual inquiry $[3,11,15,16,20,21,25,27]$. Participating in an LLC is 
significantly and positively related to all significant types of student engagement, and increasing student engagement is in turn strongly related to educational gains $[11,12,19,20,29]$. There is also strong evidence that the primary benefits of LLCs are due to the indirect impact of the increased educational engagement that LLCs provide [13].

In computer science, revisiting the introductory sequence in computing to include a focus on big ideas and applications of value to society has been showing success in increasing and diversifying participation and excitement $[4,23]$. There has also been research showing that women have better retention in the major if they have opportunities to work in small groups or pairs, and that pairs produce better results in any case [28]. Community-building, leadership, and outreach activities have also proven successful in promoting women's engagement in computing [7]. Our program incorporates these aspects.

In order to understand the impact of the program on women's engagement and persistence in computer science, a significant component of the project is the research and evaluation of the CS LLC and its impact on its participants. In this paper, we describe our living-learning community for women in computer science and our experiences with it after two cohorts of students (with the third currently participating as of this writing), in hopes that others might consider developing such programs at their own institutions.

\section{LLC PROGRAM AND PLANNING}

LLC participants live together in the same wing of one floor of a residence hall during their first year as undergraduates, and actively participate in required and optional program activities. The LLC program is supported by a staff program director, a faculty advisor, a graduate mentor, and a peer academic leader (PAL). The PAL is an upper-class student in a computing major that lives with the LLC participants. The PAL provides mentoring and academic support in the residence hall and serves as an immediate resource for LLC members. The graduate mentor is a graduate student in a computing major that assists with the operation of the LLC by helping students with their coursework and mentoring them on career development. Starting with cohort 2, we added a "big-little" mentoring program where earlier LLC students (LLC Bigs) could mentor first-year LLC students, and we arrange to hold special CS1 office hours for the LLC students. Our program draws on resources available in the CS department, the Douglass Residential College (formerly an undergraduate women's college within the university, now an intellectual community and residential program for undergraduate women within the university who chose to participate, henceforth referred to as DRC), and other parts of the university.

After their first year, LLC participants can remain connected to the program by participating as mentors in the "big-little" mentoring program, participating in selected program events, and through the social media group for all program cohorts. The social media group provides notice of various opportunities to participate in CSrelated activities at Rutgers and elsewhere, including information about potential internships and research opportunities. Students also use it to communicate across cohorts.

Our program had 18 students in cohort 1 (academic year (AY) 2016-2017) and 20 students in cohort 2 (AY 2017-2018). Cohort 3 , for AY 2018-2019, has 23 students. As we gain experience with the program and make improvements based on that experience, we envision growing the program size, perhaps up to as many as 40-50 students per year. Our expectation is that the program should be scalable to that size with only marginal increases in necessary resources. We describe our program as we have carried it out; we believe that an effective program could take place with somewhat fewer resources, such as having a single student take on the role of the PAL and the graduate mentor.

As a necessary component, running the program requires the ability to reach, and communicate with, students before they arrive on campus. It also requires communication with the housing office in order to reserve space in an appropriate residence hall and ensure the CS LLC student participants are placed there. Students in our LLC are recruited from a pool of women intending to major in CS, as indicated in their admission applications, who have been accepted into the university. Some participants have indicated that they were motivated to choose Rutgers because of the LLC. We advertise the program as part of the general admissions and recruitment process, which includes mailing and emailing marketing materials, phone calls, open houses/tours, and participation of LLC leadership in academic planning and advising days. Students must enroll at Rutgers before they can officially apply to the LLC, typically at the time that they make their on-campus housing requests. So far, we have followed the practice of accepting all eligible students who apply for the LLC until the available program slots have been filled. The program director also works with the enrollment management office to secure student scholarships for all women participating in the program as an additional benefit to LLC participants and as part of our institution's commitment to enhancing gender diversity in STEM, though this is not always possible and does not seem to be a necessary component of the program.

The program director and the faculty advisor recruit the graduate mentor, the PAL, and the LLC Bigs. For training them, we draw on the resources and experiences of DRC, which trains a larger group of graduate mentors, PALs, and Bigs. The director also works directly with other institutional offices to ensure an exceptional academic experience for the students. In collaboration with the academic advising office, students in the LLC are registered in the appropriate computer science and prerequisite or co-requisite math courses during their first semester at Rutgers. They are also given the opportunity to participate in an LLC-specific study group through our collaboration with the Rutgers Learning Center. All students have the same opportunity to participate in similar study groups for CS1 and CS2; our intervention here is to keep the LLC participants in the same study group.

The students in the LLC participate in a variety of academic, professional, and community building opportunities. Activities are a mix of events developed specifically for the LLC and those open to a broader audience (e.g., all DRC students), allowing the students to feel part of their own smaller community and the larger communities at, and beyond, our university. Professional development events range from general programs for women in STEM to CS-targeted networking opportunities and conferences. These are mostly organized by the director with assistance from the graduate mentor. Academic opportunities include the Bigs' office hours, study groups, study sessions for final exams, and the LLC's house 
course taught by the faculty advisor. Community-building opportunities are offered at multiple levels. The PAL organizes multiple activities within the residence hall while all LLC staff assist in the planning of larger community-building event, such as a welcome gathering and an end-of-year celebration.

In AY 2017-2018, there were 18 ongoing activities and events. In addition to those already mentioned, these include:

- Study Smarter, Not Harder: In collaboration with an on-campus learning center, students review a variety of study strategies that activate various types of learning used across multiple disciplines.

- Douglass Project Open House: This program introduces all DRC students in STEM to the Douglass Project for Women in STEM, including Douglass Project staff, programs, and resources available to the students.

- DRC Career Conference: This day-long conference is designed to educate DRC undergrads about career opportunities in particular industries and cross-cutting skills like networking and interviewing. The presenters are primarily Douglass alumnae, as well as other faculty and staff, and industry and nonprofit partners who work with DRC. Students hear from successful women (and some successful men) about their career paths.

- CS Industry Leader Meet and Greet: An opportunity for computer science students to meet a CS Industry leading figure. In Fall 2017, the speaker was a senior cybersecurity professional at the MITRE Corporation.

- De-Stress Fest (Fall and Spring): The De-Stress Fest aims to foster community engagement before the end of the semester and provide a "stress-free" outlet for students to unwind.

- C.A.V.E. Tour: A private tour of the C.A.V.E. (Collaborative Academic Versatile Environment) offered to demonstrate the facilities and resources available to all CS students. The space is attached to the Computer Science department's instructional labs and is designed to provide a place for student informal tutoring, collaboration, and independent exploration of CS.

- HackHERS: HackHERS is the annual, woman-centric hackathon at our university, organized by the Women in Computer Science club and the Douglass Project for Women in STEM.

- Networking Night: The goal of this event is to provide an opportunity for DRC women to practice their networking skills and develop valuable connections with participating professionals.

- Trip to Industry: This one-day field trip provides the opportunity for students to meet professionals in the field of computing and technology and ask questions related to their respective career trajectories and work experience, while receiving a tour of their facilities.

In the fall of their first year, students enroll in the DRC class Knowledge and Power required for all DRC women. In the spring, they enroll in the "house course" for the LLC, Great Ideas and Applications in Computer Science, taught by their faculty advisor. This one-credit seminar course is designed to ensure that the LLC students have a shared class experience, to connect some of the topics students are learning in CS1 and CS2 to broader applications of $\mathrm{CS}$, and to make thematic connections between various aspects of CS. The course includes high-level discussion of examples demonstrating how CS can have a positive impact on a wide variety of applications including everyday social problems; advanced science, engineering, and medical applications; journalism and politics; and commercial applications. The course also uses a few more detailed examples to highlight how underlying computational ideas such as abstraction, algorithms, and large-scale data processing play a role in these applications, as well as how programming is the enabler that turns these ideas into working systems. Students prepare brief presentations at the end of the semester on a CS-related project or topic of the students' choice, which can be a new project or something done in another course or as an extracurricular activity; students can work alone or in groups of two or three.

Students are connected to a variety of other CS-related opportunities and resources, including the Grace Hopper Celebration of Computing, a "Computing Corps" that provides CS outreach activities to middle school girls, opportunities for mentored research experiences, a variety of computing-related clubs, and CRA-W's Virtual Undergraduate Town Hall series.

\section{OUR EXPERIENCE WITH TWO COHORTS}

To understand the effectiveness of the LLC program and gain insight into the successes and potential improvements, we partnered with the Computing Research Association's Center for Evaluating the Research Pipeline (CERP), a research and evaluation center that collects and analyzes national survey data [26]. This paper is primarily about our experiences to date, including an overview in this section of our initial research findings. We hope to share more detailed research findings when they are more mature.

\subsection{Evaluation Design}

The LLC program was evaluated using a repeated measures quasiexperimental design that included both qualitative and quantitative methods to evaluate the efficacy of the program on participants' expected outcomes based on the goals of the program. LLC participants and a comparison group were surveyed at both the beginning (Time 1) and end (Time 2) of the AY. At the end of the AY, university staff held focus groups with LLC participants. CERP also carried out follow-up interviews with some members of cohort 1 . Specifically, we describe the results of evaluation activities carried out according to the following schedule:

\begin{tabular}{|l|cccc|}
\hline & $\begin{array}{c}\text { Time 1 } \\
\text { Survey }\end{array}$ & $\begin{array}{c}\text { Time 2 } \\
\text { Survey }\end{array}$ & $\begin{array}{c}\text { Focus } \\
\text { Group }\end{array}$ & $\begin{array}{c}\text { Follow-up } \\
\text { Interviews }\end{array}$ \\
\hline Cohort 1 & Oct/Nov'16 & Apr'17 & May'17 & Jun'17 \\
\hline Cohort 2 & Sep/Oct'17 & Apr/May'18 & Apr'18 & N/A \\
\hline
\end{tabular}

LLC participants were recruited by LLC staff to complete CERP's survey. To recruit the comparison group of women each year, a flyer was shared with CS1 students inviting eligible students to participate in the study. Interested students emailed a CERP liaison and were screened for eligibility. Potential comparison group students were eligible for the survey if they were not part of the CS LLC and identified themselves as first-year students, women, and interested in majoring in CS. ${ }^{1}$ Students who completed CERP's surveys were

\footnotetext{
${ }^{1} \mathrm{~A}$ possible limitation is that we did not include a requirement for living in an oncampus residential hall, which may make the comparison group less similar. We will require this for future comparison group eligibility.
} 
given a \$20 Amazon eGift card for each survey completed (Fall and Spring) as part of their participation in the study.

The CERP survey asked questions related to students' career goals and aspirations, sense of belonging and confidence in their abilities to succeed in computing, participation in various extracurricular or co-curricular activities, and satisfaction with their departments. Interviews and focus groups with LLC participants collected further details more specific to the LLC program. We overview our initial research findings for cohorts 1 and 2 in Sections 3.2 and 3.3, respectively. Quantitative results were generated using one-way Anaysis of Variance (ANOVA) and repeated measures ANOVA.

\subsection{Evaluation Results: Cohort 1}

Cohort 1, beginning AY 2016-2017, initially comprised 18 students. One student went on medical leave early in the fall semester and did not participate in the evaluation activities. Accordingly, these results only include $n=17$ LLC participants. The cohort 1 comparison group comprised $n=34$ students. The self-reported demographics of both groups are as follows:

\begin{tabular}{|l|cccc|c|}
\hline & Asian & Black & White & $\begin{array}{c}\text { Multi } \\
\text { Other }\end{array}$ & U.S. Citizen \\
\hline Participants & $53 \%$ & $12 \%$ & $29 \%$ & $6 \%$ & $71 \%$ \\
\hline Comparison & $79 \%$ & $3 \%$ & $15 \%$ & $3 \%$ & $79 \%$ \\
\hline
\end{tabular}

3.2.1 Cohort 1: Survey Results. Before measuring changes from Time 1 to Time 2, CERP examined Time 1 data to understand if the LLC group and the comparison group differed in any of the outcomes in this study. Time 1 data indicated that LLC participants and comparison students were statistically equivalent on most outcomes in this study, with the following exceptions:

- The comparison group was more interested in pursuing an interdisciplinary non-research career and more satisfied with the computing program at the university than LLC students.

- LLC participants reported more mentor support and were more involved in some computing-related activites than the comparison group.

Next, we measured whether students' responses at Time 2 differed from Time 1. Results indicated LLC and comparison groups reported statistically equivalent change over time on most outcomes in this study. Exceptions included the following:

- LLC participants reported stronger beliefs that computing ability is inborn; the comparison group showed no change.

- LLC participants reported less satisfaction with computing courses at the university and perceived a less supportive environment in the computing department over time; the comparison group showed no change.

- LLC participants participated in more conferences and attended more lectures during the school year than the comparison group.

- LLC participants show a significant decrease in computing selfefficacy over time. The comparison group also shows a decrease in computing self-efficacy over time, albeit to a lesser degree than LLC participants.
3.2.2 Cohort 1: Focus Group Results. A research faculty member held a focus group with four LLC participants before the end of the AY. Focus group participants spoke very positively about the LLC and its impact on their college experience. They also spoke highly of the faculty, staff, and mentors associated with the program; however, participants noted they did not know the graduate mentor well, which may be because she was not hired at the start of the program and she was not available on weekends.

Completing the sentence "My year in the LLC has...," participants said the following:

... "enhanced my drive in continuing with CS because I have a group of people for support."

... "impacted me so much. As an international student, I can't imagine how my first year would be without the LLC. In such a big campus, making close friends is hard. With the LLC's impact, I am more confident about my academic goal."

... "been truly an amazing experience. I couldn't have asked for a better first year experience...."

... "[was] a year full of amazing support and new friendships that will last a lifetime."

3.2.3 Cohort 1: Interview Results. CERP carried out interviews with five LLC participants via phone or Skype in June 2017. Questions were framed to gain insight into how the LLC might have contributed to participants' low satisfaction with the CS department, beliefs about the nature of computing ability, and low computing self-efficacy.

When asked for their opinions about the CS department, interviewees had both positive and negative things to say, including:

"I would recommend this department to a senior in high school. I like how welcoming some professors and organizations (USACS) could be. They are willing to help as long as you come prepared with questions."

"... [the department doesn't] like to encourage group work. Sometimes group work is the best way to succeed, like getting other people's opinions and ideas and working together."

Interviewees indicated they were not confident when they started college, even those with some CS pre-college background. Some also talked about how participating in the LLC helped boost their confidence:

"[When I started college, I was] scared! Everyone said CS was hard, and I barely knew anything. I took AP classes, but I didn't learn much from it. So I didn't take the exam or anything."

"I was definitely scared. After doing the LLC, I realized that pretty much everyone is the same. Pretty much everyone doesn't know anything. So I feel better.... If I didn't join the LLC, I probably would have worked alone, so I probably would have stopped like halfway...I feel like I can handle it now with my peers. And if it's by myself, I would definitely give up."

Regarding beliefs about the nature of computing intelligence, some aspects of the responses showed a growth mindset, while others indicate a belief that computing skills come more naturally to some people than others: 
"It's not like you're born with it. You practice it, you learn the skill. The more you practice, the more you will get used to it.... So I think it's a muscle training thing. ... At the beginning of the year, I felt like some people [were] just good at it ... But later on, I realized everyone is just the same. People start from the introduction classes, and [now I feel like] I can handle it."

"I initially thought computing skills is something you are born with, like everyone must be super good coders because they were born with this ability to think and process a certain way. But I think after taking my first intro classes, I've moved on from that. I am starting to see that it's not something people are born with, but it's something they have learned through thinking a specific way or through practicing the process."

Students talked at length about positive impacts of the LLC including the sense of community, access to information and resources, and mentorship:

"I would recommend this LLC for high school students. [Regarding] Douglass as a woman in this field, I felt kind of alone before I came in. Because everyone is saying CS is really hard for a woman. Even my mom still doesn't think it's a good idea. But after doing this LLC I feel really supported. Actually there are a lot of women like me doing the same thing, so I would recommend women do this."

"I've had girls who weren't in the LLC write me and say "you guys are so lucky, I wish I signed up for this, it's always nice to have a community...”

"The peer leader would always encourage us to take CS no matter what. She would always help us with any questions or concerns we had. I think it was helpful to have someone our age giving us advice."

"In the LLC we would also talk about if we weren't in the LLC we didn't think we would have continued with CS.... This community has helped me especially make it through to study CS. ... I think it was the fact that I was able to work with a group of women going through the same struggles as me, understanding what I was feeling, was a really important thing to succeed. And I was able to find people who are not only good to work with in school, but good friends."

Participants also noted that they felt the LLC suffered due to some participants who didn't significantly engage with the group and weren't as interested in CS from the start:

"There was a group of us that I was in, like 10-12 people that connected very well. There were a few people who kind of stayed to themselves... We tried to get everyone involved but it's hard.... We would do activities and a lot of them wouldn't show up."

"My roommate didn't know she was part of the LLC [upon arriving to campus in the fall]. Maybe it was because she was an international student, but I thought the person I was living with would be part of the LLC, and then I asked her and she said "I'm not even sure I want to do CS" I was like... Ok. It was a weird experience because I wasn't sure who was part of the LLC. Some people weren't sure what they signed up for."

Based on feedback from the cohort 1 participants as well as our direct experiences with the program, we made changes to ensure that the LLC participants understood that the program was directed to women wanting to major in computer science and that participants were intended to be an active part of the community. To this end, we began requiring LLC applicants to write a few sentences about why they want to study computer science and why they want to be in the LLC program.

\subsection{Evaluation Results: Cohort 2}

Cohort 2, beginning AY 2017-2018, initially comprised 20 students; however, one student went on leave in the fall semester and was not included in the analysis. Another student joined the program during the spring and was not included in survey distribution or the original cohort count. With changes in participants and nonresponse from two other students, the final sample for cohort 2 was $n=17$ LLC students and $n=32$ comparison group students. The self-reported demographics of both groups are as follows:

\begin{tabular}{|l|cccc|c|}
\hline & Asian & Black & White & $\begin{array}{c}\text { Multi } \\
\text { Other }\end{array}$ & U.S. Citizen \\
\hline Participants & $65 \%$ & $6 \%$ & $0 \%$ & $30 \%$ & $75 \%$ \\
\hline Comparison & $77 \%$ & $0 \%$ & $20 \%$ & $3 \%$ & $77 \%$ \\
\hline
\end{tabular}

3.3.1 Cohort 2: Survey Results. Prior to examining any changes from Time 1 to Time 2 among cohort 2 students, we looked at differences between the comparison group and LLC participants at Time 1. Results were similar to findings for cohort 1 . For most measures, both groups were statistically equivalent with the following exception:

- LLC participants reported stronger mentor support than the comparison group.

Next, we examined changes over time; results yielded both positive and concerning findings:

- LLC participants were more likely than the comparison group to indicate they intended to pursue their highest degree in a computing field at both Time 1 and Time 2 .

- A higher proportion of LLC participants stayed in their CS major over time (88\%) than the comparison group (53\%).

- LLC participants reported stronger levels of mentorship overall than the comparison group.

- LLC participants reported more involvement in computing related activites (e.g., conferences, lectures by women, student groups).

- Both LLC participants and comparison students reported the following to the same degree over time:

- weaker computing self-efficacy.

- weaker belief that a career in computing could afford them opportunities to serve humanity and be in a position of influence in society.

- stronger beliefs that computing ability is inborn.

- stronger interest in non-computing careers.

- less satisfaction with the computing program.

- stronger feelings of threat.

- weaker department support.

- While LLC participants reported overall stronger mentor support and peer support than the comparison group, an interaction effect revealed that LLC participants's perceived mentor support was weaker at Time 2 while the comparison group's perceived mentor support was stronger at Time 2 . 
3.3.2 Cohort 2: Focus Group Results. As with cohort 1, we held a focus group at the end of the spring semester with 14 LLC cohort 2 participants. Major findings from the focus group are as follows:

- Students shared positive evaluations of all staff associated with the LLC. Suggestions for improvement largely focus on programmatic and structural elements, such as more resources and clearer guidelines for how to use resources.

- The LLC is important for helping participants make connections with other students. This facet could be further strengthened, with student suggestions for improving the connectedness of students to one another and to computer science including: more hands-on activities, study groups, assignment to the same course sections, continued physical proximity after the first year, and additional events for the group.

- LLC participants were overwhelmingly positive about the role of their PAL peer mentor. They did not seem to benefit from peer mentoring relationships with the members of cohort 1 .

- Students very much appreciated the trip to the tech firm in NYC and viewed it as a positive opportunity for both individual and cohort development.

Students were asked what aspects of the program worked well. The following quotes are examples from that discussion:

"[The visit to the tech company] worked because we all came together, and we all saw where we can be in the future if we work hard ... it opened our eyes up to why we should continue."

"[Living in the LLC] kept me more in touch with my major. Although there aren't a lot of resources, there are more than one would get if they were not a part of LLC."

One woman who described herself as shy said the LLC helped her make close friends and that-in a positive way-she is "literally completely different" than she was in high school. Asked to explain, she said participating in the LLC: "made me realize that this is the person I am." An international student noted that when she came to the university, she knew no one, but that living in the LLC helped her make friends: "I know people, I am making friends, I feel like, ok, I am not alone."

Suggestions for improvement from participants included the following:

- Clarify the role of the graduate mentor.

- More hands-on activities in the house course.

- Hold the house course during the fall semester.

\section{LESSONS LEARNED AND FUTURE PLANS}

Overall, evaluation findings between cohorts 1 and 2 suggest that while the program has not made dramatic impacts on students' outcomes over time, LLC participants describe the program as being important to them, and tend to report more mentor support than other women who are not in the LLC program. LLC participants also seem to have stronger intentions to persist in CS than the comparison group. However, both the LLC participants and the comparison group show concerning trends over time, which we will continue to address in coming years.

Since the psychological and aspirational outcomes decreased over time for both groups of women, we speculate that the reason for this decline is likely not due to women's participation in the LLC program. Instead, the research findings point to a potentially larger issue that affects first-year women in CS broadly at Rutgers (as well as possibly men and students at other institutions). These results also imply that the LLC program does not act as a "buffer" to environmental or cultural threats to the extent we might have expected. On the positive front, LLC women were more likely than the comparison group to report engagement in extracurricular activities related to women in computing. Engagement in these activities may help women's persistence in the long-term, because activities like conferences and groups for women expose students to real-world contexts, research innovations, and opportunities to broaden their professional networks. Nonetheless, simply continuing to increase engagement through an increased number of activities may not be a good approach because of the increased time commitment. We will work to understand these tradeoffs and relationships better in future assessments.

As a result of our cohort 1 evaluation findings, we modified our recruitment process to ensure that students understand that the program is intended for students who plan to major in CS (even if they have not yet had formal computing experience). Additionally, we are tracking the academic progression of students in the LLC to determine whether or not they persist through the CS intro sequence and ultimately declare a CS major. Students cannot declare a CS major at our institution until they have successfully completed this sequence, so we are only just now beginning to see some cohort 1 students declare a CS major.

We also made some changes regarding the graduate student mentor, as students from both cohorts felt they were unable to get to know the graduate mentor very well. During the second year, we ensured that the graduate mentor was hired by the start of the program, but evaluation findings show we still have room for improvement. We will continue to find more ways to foster interaction between LLC participants and the graduate mentor. Another lesson learned related to the need to be resilient to administrative delays outside of our control, as these caused disruption to our plans in multiple ways. Based on the excitement students reported in visiting local companies, and because the first cohort is now reaching the point in their studies where they interested in internships and thinking about post-college employment opportunities, we are working to have more interaction with industry. For example, we are looking to include additional student visits to industry sites, and we plan to hold panels and other activities on campus with tech industry participants.

The "big-little" mentoring of cohort 1 by cohort 2 was not as robust as we would like for this mentoring program. In the coming year, we are hoping to improve this aspect of the program through training sessions for the mentors from earlier cohorts and inviting them to participate in the welcome event and other selected LLC activities. Ideally, these modifications will enable the big-little mentoring program to serve two valuable purposes: providing additional mentoring for each new cohort and keeping earlier cohorts closely connected to the program.

Future work will continue to monitor the program and its participants in partnership with CERP. We will continue to make changes to the program based on evaluation results and seek a better understanding of the factors that may contribute to concerning results 
learned during the evaluation process. Because of the modest size of our program, the evaluation findings suffer from small sample sizes in each cohort. Combining samples over multiple years as the program progresses will yield larger sample sizes, allowing for a more reliable analysis than we can currently have. Larger sample sizes will also allow for the analysis of results based on demographic groups, which may also help explain some of the results to date.

We will continue to examine the impact of the LLC program with the third cohort. CERP has revisited the survey instrument to incorporate other measures that may point more directly to outcomes of the LLC program and ensure survey items are relevant to the respondents. If possible, CERP may also follow up with the first cohort of LLC and comparison students through surveys and/or interviews to understand if there are any long-term impacts of the LLC program undetected by the short-term results. Using CERP's Data Buddies Survey [26], we may also add a comparison group of men from our university to determine whether men demonstrate a similar downward trend from the start to the end of the academic year on psychological and aspirational outcomes, as well as compare our results with first-year students at other schools. With cohort 4 , we plan to grow the program to 24-30 students.

As the early LLC cohorts reach the point of declaring majors, we will also track various kinds of retention and success: what proportion stay at Rutgers, declare and persist in a CS major or related major, how do they perform academically, what they go on to do after their undergraduate degree, and how do these compare to other students. Additionally, we will continue to seek more ways to keep the LLC participants engaged in the community as they progress through their time at Rutgers, as well as ways for current students to engage with graduated LLC participants (once we have them).

We hope that others may learn from our experience to develop similar programs at their institutions. Our program built heavily on the experience of DRC in running LLCs for women in other STEM areas, and we recommend that institutions draw on the specific resources at their institutions. In addition, we hope that knowledge from our program will smooth the pathway for programs even at institutions that do not have something like DRC to draw on. Ultimately, we hope this living-learning community-and others that might be developed like it-will help diversify the computing workforce by inspiring and motivating new generations of students to pursue degrees in CS and careers in technology broadly defined.

\section{ACKNOWLEDGMENTS}

This work was funded by the National Science Foundation under grant \#1504775.

\section{REFERENCES}

[1] National Academies. 2007. Beyond Bias and Barriers: Fulfilling the Potential of Women in Academic Science and Engineering. The National Academies Press.

[2] National Academies. 2018. Assessing and Responding to the Growth of Computer Science Undergraduate Enrollments. The National Academies Press.

[3] C. Allen. 1999. Wiser women: Fostering undergraduate success in science and engineering with a residential academic program. fournal of Women and Minorities in Science and Engineering 5, 3 (1999), 265-277.

[4] Christine Alvarado, Zachary Dodds, and Ran Libeskind-Hadas. 2012. Increasing Women's Participation in Computing at Harvey Mudd College. ACM Inroads 3, (2012), 55-64.
[5] Jayne E. Brownell and Lynne E. Swaner. 2010. Five high-impact practices: Research on learning outcomes, completion and quality. Association of American Colleges and Universities.

[6] S. Cheryan, V.C. Plaut, P.G. Davies, and C.M. Steele. 2009. Ambient belonging: How stereotypical cues impact gender participation in computer science. Journal of Personality and Social Psychology 97 (2009), 1045-1060.

[7] Teresa Dahlberg, Tiffany Barnes, Kim Buch, and Karen Bean. 2010. Applying service learning to computer science; attracting and engaging underrepresented students. Computer Science Education 20, 3 (2010), 169-180.

[8] National Science Foundation. 2003. New Formulas for America's Workforce: Girls in Science and Engineering. National Science Foundation.

[9] Faith Gabelnick, Jean MacGregor, Roberta S. Matthews, and Barbara Leigh Smith. 1990. Learning Community Models). New directions for teaching and learning 41 (1990), 19-37.

[10] Catherine Hill, Christianne Corbett, and Andresse St. Rose. 2010. Why so Few? Women in Science, Technology, Engineering, and Mathematics. American Association of University Women.

[11] K.K. Inkelas, Z.E. Daver, K.E. Vogt, and J.B. Leonard. 2007. Living-Learning programs and first-generation college students' academic and social transition to college. Research in Higher Education 48, 4 (2007), 403-434.

[12] Karen Kurotsuchi Inkelas. 2004. Does participation in ethnic cocurricular activities facilitate a sense of ethnic awareness and understanding? A study of Asian Pacific American undergraduates. Journal of College Student Development 45, 3 (2004), 285-302.

[13] Karen Kurotsuchi Inkelas. 2008. National study of Living-Learning programs: 2007 report of findings. Technical Report http://hdl.handle.net/1903/8392. University of Maryland.

[14] Karen Kurotsuchi Inkelas. 2011. Living-learning programs for women in STEM. New Directions for Institutional Research 152 (2011), 27-37.

[15] K. K. Inkelas, K.E. Vogt, S.D. Longerbeam, J. Owen, and D. Johnson. 2006. Measuring outcomes of living-learning programs: Examining college environments and student learning and development. The Journal of General Education 55, 1 (2006), 40-76.

[16] Karen Kurotsuch Inkelas and Jennifer L. Weisman. 2003. Different by design: An examination of student outcomes among participants in three types of LivingLearning programs. Fournal of College Student Development 44, 3 (2003), 335-368.

[17] Karyn L. Lewis, Jane G. Stout, Noah D. Finkelstein, Steven J. Pollock, Akira Miyake, Geoff L. Cohen, and Tiffany A. Ito. 2017. Fitting in to Move Forward: Belonging, Gender, and Persistence in the Physical Sciences, Technology, Engineering, and Mathematics (pSTEM). Psychology of Women Quarterly 41, 4 (2017).

[18] Jane Margolis, Allan Fisher, and Faye Miller. 2000. The anatomy of interest. Women's Studies Quarterly 28, 1/2 (2000), 104-127.

[19] Gary Pike, George Kuh, and Alexander McCormick. 2011. An investigation of the contingent relationships between learning community participation and student engagement. Research in Higher Education 52, 3 (2011), 300-322.

[20] Gary R. Pike. 1999. The effects of residential learning communities and traditional residential living arrangements on educational gains during the first year of college. Journal of College Student Development 40, 3 (1999), 269-284.

[21] Louis Rocconi. 2011. The impact of learning communities on first year students' growth and development in college. Research in Higher Education 52, 2 (2011), 178-193.

[22] Nancy S. Shapiro and Jodi H. Levine. 1999. Creating Learning Communities: A Practical Guide to Winning Support, Organizing for Change, and Implementing Programs. Jossey-Bass.

[23] Lawrence Snyder, Tiffany Barnes, Dan Garcia, Jody Paul, and Beth Simon. 2012. The First Five Computer Science Principles Pilots: Summary and Comparisons. ACM Inroads 3, 2 (2012), 54-57.

[24] Matthew Soldner, Heather Rowan-Kenyon, Karen K.urotsuchi Inkelas, Jason Garvey, and Claire Robbins. 2012. Supporting students' intentions to persist in STEM disciplines: The role of living-learning programs among other socialcognitive factors. The fournal of Higher Education 83, 3 (2012), 311-336.

[25] Martha L. A. Stassen. 2003. Student outcomes: The impact of varying livinglearning community models. Research in Higher Education 44, 5 (2003), 581-613.

[26] Jane Stout. 2013. Center for Evaluating the Research Pipeline (CERP): Providing a New Way to Evaluate Diversity Initiatives in Computing Research. Computing Research News 25, 7 (Aug. 2013). https://cra.org/crn/category/2013/vol-25no-7/

[27] Katalin Szelenyi and Karen Kurotsuchi Inkelas. 2011. The role of living-learning programs in women's plans to attend graduate school in STEM fields. Research in Higher Education 52, 4 (2011), 349-369.

[28] Linda Werner, Brian Hanks, and Charlie McDowell. 2004. Pair-Programming Helps Female Computer Science Students. ACM Journal of Educational Resources in Computing 4, 1 (2004).

[29] Chum-Mei Zhao and George Kuh. 2004. Adding value: Learning communities and student engagement. Research in Higher Education 45, 2 (2004), 115-138.

[30] Stuart Zweben and Betsy Bizot. 2018. 2017 CRA Taulbee Survey: Another Year of Record Undergrad Enrollment; Doctoral Degree Production Steady While Master's Production Rises Again. Computing Research News 30, 5 (May 2018). https://cra.org/crn/category/2018/vol-30-no-5/ 